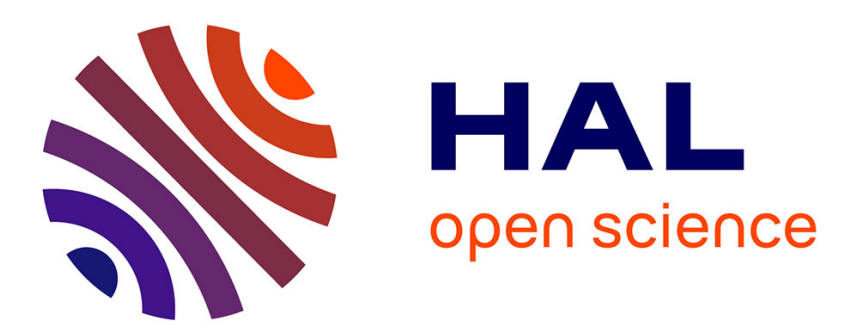

\title{
On Residual Stresses Development During Nitriding of Steel: Thermochemical and Time Dependence
}

\author{
Sebastien Jegou, Regis Kubler, Laurent Barrallier
}

\section{To cite this version:}

Sebastien Jegou, Regis Kubler, Laurent Barrallier. On Residual Stresses Development During Nitriding of Steel: Thermochemical and Time Dependence. Advanced Materials Research, 2010, 89-91, pp.256-261. 10.4028/www.scientific.net/AMR.89-91.256 . hal-01326243

\section{HAL Id: hal-01326243 \\ https://hal.science/hal-01326243}

Submitted on 3 Jun 2016

HAL is a multi-disciplinary open access archive for the deposit and dissemination of scientific research documents, whether they are published or not. The documents may come from teaching and research institutions in France or abroad, or from public or private research centers.
L'archive ouverte pluridisciplinaire HAL, est destinée au dépôt et à la diffusion de documents scientifiques de niveau recherche, publiés ou non, émanant des établissements d'enseignement et de recherche français ou étrangers, des laboratoires publics ou privés. 


\title{
On Residual Stresses Development During Nitriding of Steel: Thermochemical and Time Dependence
}

\author{
S.Jegou ${ }^{1, a}$, R.Kubler ${ }^{1, b}$ and L.Barrallier ${ }^{1, c}$ \\ ${ }^{1}$ Arts \& Metiers ParisTech, MecaSurf Laboratory, 13100 Aix-en-Provence, France \\ a sebastien.jegou-0@etudiants.ensam.eu, ${ }^{b}$ regis.kubler@ensam.eu, ${ }^{\mathrm{C}}$ laurent.barrallier@ensam.eu
}

Keywords: nitriding, residual stress, precipitation, thermochemical treatment, kinetic, modeling

\begin{abstract}
This work deals with the development of residual stresses during nitriding of steels. The main features of a chemico-thermo-mechanical model of nitriding are presented. A micro-macro approach is applied based on volume change computation in agreements with thermochemical modifications. Results are correlated with the characterization of a ternary $\mathrm{Fe}-\mathrm{C}-3 \mathrm{w} . \% \mathrm{Cr}$ alloy nitrided at $550^{\circ} \mathrm{C}$ for various time. Residual stress-depth analyses are carried out by X-rays diffraction. Residual stress generation is deeply dependant on chemical and thermodynamical evolutions during the treatment, taking advantage on microstructural effects.
\end{abstract}

\section{Introduction}

Nitriding is a widely used process over the possible thermochemical surface treatment of steels in order to improve the superficial mechanical properties such as the fatigue, wear and corrosion properties $[1,2,3]$. The treatment is based on diffusing nitrogen through a surface and involves the precipitation of sub-microscopic and semi-coherent nitrides $\mathrm{MN}(\mathrm{M}=\mathrm{Cr}, \mathrm{V}, \mathrm{Mo} \ldots)$. In order to adjust surface properties with respect to the design of mechanical parts, knowledge about residual stress development are failing. Origins of residual stresses have been attributed to volume changes (precipitation and content evolutions) and thermal effects $[4,5,6]$. With the composition gradient, an in-depth gradient of residual stresses develops with a low stress level below the surface and a maximum of stress deeper in the material. In case of binary iron alloys (e.g. FeCr), residual stresses are explained by the microstructural evolution of sub-microscopical MN until a discontinuous precipitation close to the surface [7]. In case of carbon-based alloys, these explanations are not satisfying as discontinuous precipitation is not observable through a nitrided surface [8,9]. Moreover microstructural evolution is not evident and even exhibits an unusual tendency with a bigger size of MN nitrides deeper in the nitrided surface, close to the maximal residual stress and nitrogen diffusion front $[9,10]$. In fact, a second kind of MN precipitation takes place based on the transformation of annealing carbides into nitrides. Carbon released into the matrix is so able to diffuse with nitrogen and makes more complex metallurgical changes during the treatment (carbides precipitation such as $\mathrm{M}_{3} \mathrm{C}, \mathrm{M}_{7} \mathrm{C}_{3}, \mathrm{M}_{23} \mathrm{C}_{6}$ ). Thus the microstructure may not only explain residual stress development in such heterogeneous materials. This paper deals so with residual stress generation based on chemical and thermodynamical changes during the treatment. The main features of a nitriding model is presented and compared to some experimental characterizations of a synthetic carbon iron-based alloy.

\section{Nitriding model}

The mechanical approach is based on a self-consistent scheme in agreements with experimental Xrays analysis $[4,11,12,13,14]$ and needs the determination of eigenstrain of each phase at each nitrided depth. Therefore the volume change $\left(\varepsilon_{\Phi i}^{v}=\frac{1}{3} \frac{\Delta V}{V}\right)$ accompanying the precipitation as well as the volume fraction of created precipitates must be. The nitriding model is so split in three parts briefly described below. 
Diffusion/Precipitation: As the few models in the literature [15,16], nitrogen and carbon diffusion consists in resolving the Fick's Second Law using the Crank-Nicolson method [17]. However the originality lies in a Thermo-Calc interface written in $\mathrm{C}$ language in order to resolve phase stability depending on nitrogen and carbon content gradient. The in-depth chemical composition of each phase $\omega_{\Phi i}^{Z j}$ is so obtained. Moreover experimental nitrogen and carbon content profiles can be used as input data aiming comparisons with different experimental techniques.

Volume change calculation: The volume change estimation $\frac{\Delta V}{V}$ requires the computation of the phase specific volume in agreement with the phase composition. The specific volume $v_{\Phi i}$ and then the volume of precipitates $V_{p}$ before nitriding are defined by:

$$
v_{\Phi i}=\frac{V_{\text {lattice }} \cdot A}{\sum_{j=1}^{q} N_{\Phi i}^{Z j} \cdot M^{Z j}} \quad \text { and } \quad V_{p}=m \cdot \sum_{i=2}^{n} v_{\Phi i} \cdot \omega_{\Phi i}
$$

where $V_{\text {lattice }}$ is the elementary volume of lattice of phase $\Phi_{i}, A$ is the Avogadro's number, $N_{\Phi i}^{Z j}$ the stoichiometric coefficient of element $Z_{\mathrm{j}}$ in phase $\Phi_{\mathrm{i}}, M^{Z_{j}}$ the molar weight of element $Z_{\mathrm{j}}$ and $m$ is the total mass of the system and $\omega_{\Phi i}$ the weight percent of phase $\Phi_{\mathrm{i}}$ before nitriding.

While new elements are added to the system due to nitrogen and carbon diffusion, the mass increase $\Delta m$ between time $t-1$ and $t$ is calculated assuming that heavy elements $(\mathrm{Fe}, \mathrm{Cr}, \mathrm{V} \ldots)$ do not diffuse during the treatment. Defining the quantity of heavy elements $\omega^{Z j}$ at $t-1$ and $\omega^{\prime Z j}$ at $t$, the mass increase and the new volume of precipitates $V_{p}^{\prime}$ are:

$$
\Delta m=m \cdot\left(\sum_{j=1}^{p} \omega^{Z j} / \sum_{j=1}^{p} \omega^{\prime Z j}\right) \quad \text { and } \quad V_{p}^{\prime}=(m+\Delta m) \cdot \sum_{i=2}^{n} v_{\Phi i} \cdot \omega_{\Phi i}^{\prime} .
$$

Mechanical modeling: Residual stresses in each phase (ferrite and precipitates) are computed based on an idealized microstructure of precipitates embedded in a ferritic matrix after nitriding. A self-consistent scheme is adopted. Since local (phase level) and global (macroscopic level) scales are considered, the notation for global values is $\hat{X}$. The model supposes a homogeneous and isotropic semi-finite plane volume element with the small strain assumption. As observed experimentally, a nitrided surface is under a macroscopic plane stress state ( $\mathrm{z}$ being the depth):

$$
\forall z, \hat{\varepsilon}_{x y}=\hat{\varepsilon}_{y x}=0 \text { and } \hat{\sigma}_{x y}=\hat{\sigma}_{y x}=0 .
$$

Moreover due to their nano-scale natures, the precipitate's behavior is assumed fully elastic (i.e. $\varepsilon_{\text {precipitates }}^{p}=0$ ) whereas the ferritic matrix is considered elasto-plastic. Constitutive equations are written as follows depending on the considered scale and kinetics:

- Macroscopic equations based on equilibrium equations. Equation of strain compatibility is also used in order to take into account the in-depth gradient of strain. $\underline{\hat{\varepsilon}}^{l}$ represents the eigenstrain rate tensor divided into $\underline{\hat{\varepsilon}}^{p}$ and $\underline{\hat{\varepsilon}}^{\text {tr }}$ the plastic and the phase transformation strain rate respectively :

$$
\left\{\begin{array}{l}
\dot{\hat{\hat{\varepsilon}}}=\dot{\hat{\hat{\varepsilon}}}^{e}+\dot{\hat{\hat{\varepsilon}}}^{l}=\dot{\hat{\hat{\varepsilon}}}^{e}+\dot{\hat{\hat{\varepsilon}}}^{p}+\underline{\dot{\hat{\varepsilon}}}^{t r} \\
\operatorname{div} \underline{\hat{\sigma}}=0 \\
\hat{\hat{\varepsilon}}_{i j, k l}-\hat{\varepsilon}_{i k, j l}=\hat{\varepsilon}_{l j, k i}-\hat{\varepsilon}_{l k, j i}
\end{array} .\right.
$$


The phase transformation strain rate is defined by [18]:

$$
\underline{\dot{\varepsilon}}_{\Phi i}^{t r}=\dot{y}_{\Phi i} \cdot \underline{\varepsilon}_{\Phi i}^{v}=\dot{y}_{\Phi i} \cdot \frac{1}{3} \cdot \frac{\Delta V}{V} .
$$

where $\dot{y}_{\Phi i}$ is the volume fraction rate corresponding to the phase transformation and $\underline{\varepsilon}_{\Phi i}^{v}$ the volumic eigenstrain of phase $\Phi_{i}$.

- Local equations that are phenomenological behavior laws of ferrite and precipitates:

$$
\left\{\begin{array}{l}
\underline{\dot{\varepsilon}}_{\Phi i}=\underline{\dot{\varepsilon}}_{\Phi i}^{e}+\dot{\dot{\varepsilon}}_{\Phi i}^{l}=\underline{\dot{\varepsilon}}_{\Phi i}^{e}+\underline{\dot{\varepsilon}}_{\Phi i}^{p}+\underline{\dot{\varepsilon}}_{\Phi i}^{t r} \\
\underline{\dot{\sigma}}_{\Phi i}=\underline{\underline{C}}_{\Phi i}: \dot{\varepsilon}_{\Phi i}^{e} \\
\dot{\underline{\sigma}}_{\alpha-F e}=g\left(\dot{\varepsilon}_{\alpha-F e}^{p}\right)
\end{array} .\right.
$$

where $\underline{\underline{C}}_{\Phi i}$ is the stiffness tensor of phase $\Phi_{i}, g\left(\underline{\dot{\varepsilon}}_{\alpha-F e}^{p}\right)$ the hardening law of ferrite (power-law type with yield stress) without taking into account the microstructure.

- Scale transition equations with the help of the Eshelby's tensor $\underline{\underline{S}}^{E s h}$ expressing the general shape of inclusions, $\underline{\underline{I}}$ the unity tensor and $\underline{\underline{U}}$ the polarization tensor. These equations are a complex representation of common mixing laws and render the behavior of heterogeneous materials:

$$
\left\{\begin{array}{l}
\underline{\dot{\varepsilon}}^{e}=(\underline{\underline{I}}+\underline{\underline{U}}): \underline{\dot{\hat{\varepsilon}}}^{e}+(\underline{\underline{I}}+\underline{\underline{U}}):\left(\underline{\underline{S}}^{E s h}-\underline{\underline{I}}\right):\left(\underline{\dot{\varepsilon}}^{l}-\underline{\dot{\hat{\varepsilon}}}^{l}\right) \\
\dot{\hat{\hat{\sigma}}}=\sum_{i} y_{\Phi i} \cdot \underline{\dot{\sigma}}_{\Phi i}
\end{array} .\right.
$$

It has to be noticed that residual stresses in the ferritic matrix is expressed as the mean stress $\sigma_{11}-\sigma_{33}$ in order to be able to correlate results obtained by X-rays diffraction analysis and the $\sin ^{2} \psi$ method [13,19]. In fact, even if nitriding involves a macroscopic plane stress state $\left(\hat{\sigma}_{33}=0\right)$, the local scale (phase level) may be disturbed and so under a tri-axial stress state [20]. As a consequence, developing the $\sin ^{2} \psi$ equations results in the determination of the mean stress $\sigma_{11}-\sigma_{33}$ at the local scale [21].

Finally, those equations are solved with an iterative Newton-Raphson scheme and implemented in a ADA program in order to output residual stress-depth profiles in each phase.

\section{Experimental Dataset}

Material investigated in this study is a ternary iron-based alloy $\mathrm{Fe}-\mathrm{C}-3 \% \mathrm{Cr}$. It was nitrided at $550^{\circ} \mathrm{C}$ during 10 and 100 hours. The nitrogen and carbon content-depth profiles were obtained by glow discharge optical emission spectroscopy analysis. Residual stress analyses were carried out using conventional X-rays diffraction analysis and the $\sin ^{2} \psi$ method. Electrochemical layer removal method was used for in-depth analysis.

\section{Results}

Fig. 1 represents the results of the model in case of thermodynamical prediction, volume change calculation and finally micro-macro mechanical simulation corresponding to both treatments. An enrichment of carbon characterizes the end of the diffusion layer in both cases. This was already mentioned in the literature [22] but never takes into account in thermodynamical and residual stress calculus. The corresponding depths show an increase of the annealing carbide $\mathrm{M}_{7} \mathrm{C}_{3}$ weight fraction. The maximal volume change is estimated around $19 \%$ in both cases. Residual stresses are 
greatly decreasing between 0 and $300 \mu \mathrm{m}$ after 10 and 100 hours respectively that corresponds in fact to a decarburization of the surface. It involves so an instability of cementite $\mathrm{M}_{3} \mathrm{C}$ that disappears at these depths whereas the quantity of MN nitrides stays stable. These phase transformations result finally in an important decrease of volume change accompanying the precipitation. Moreover residual stresses are increasing much slower where the surface already experienced nitriding and carbon enrichment $(350-500 \mu \mathrm{m})$ than in depths where the material is nitrogen-free.

a.

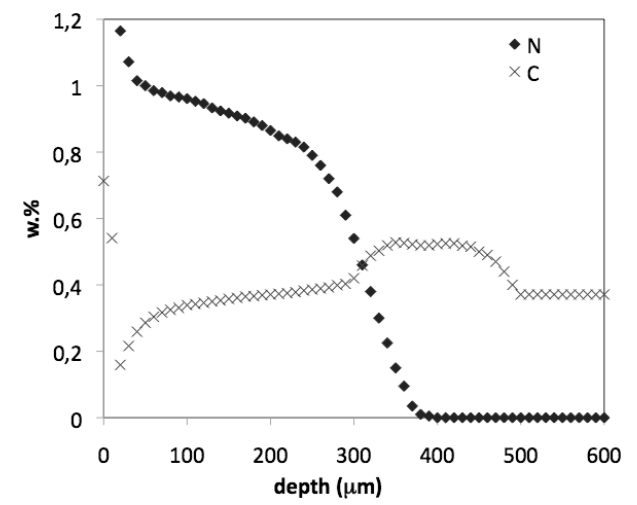

b.

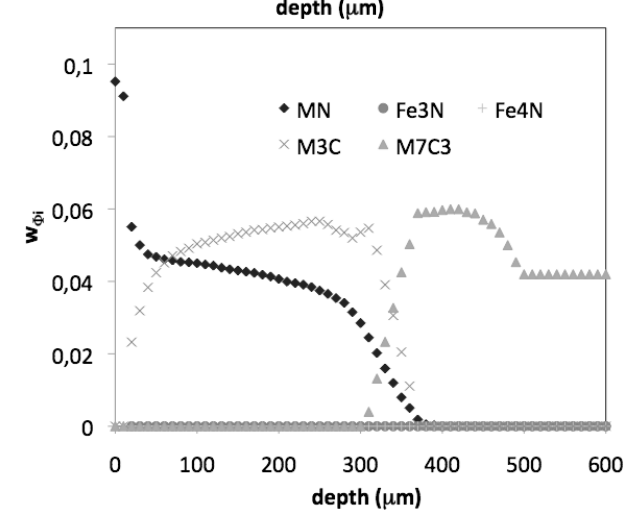

c.

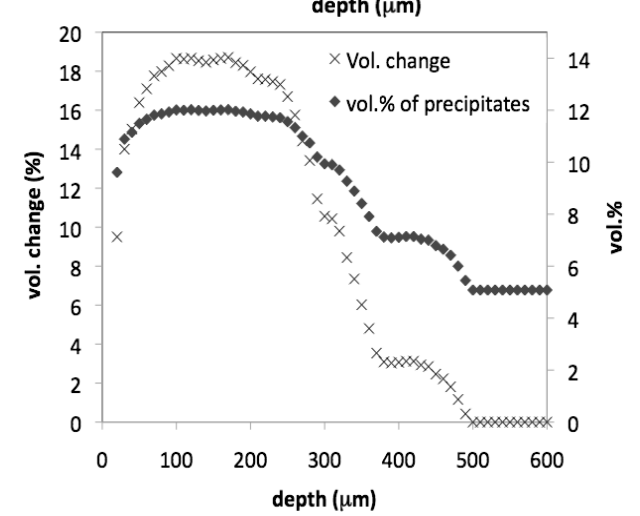

d.

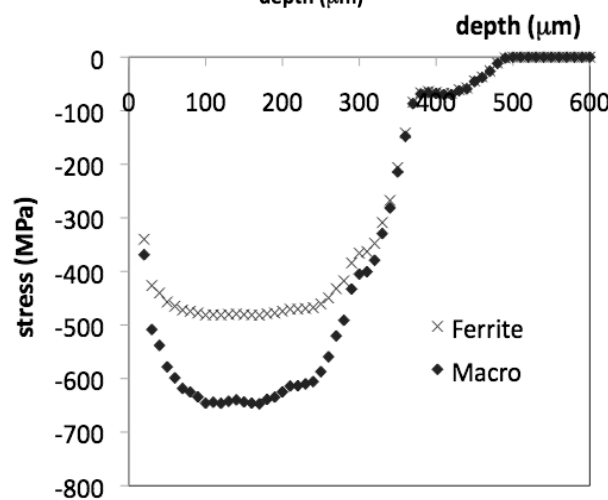

e.

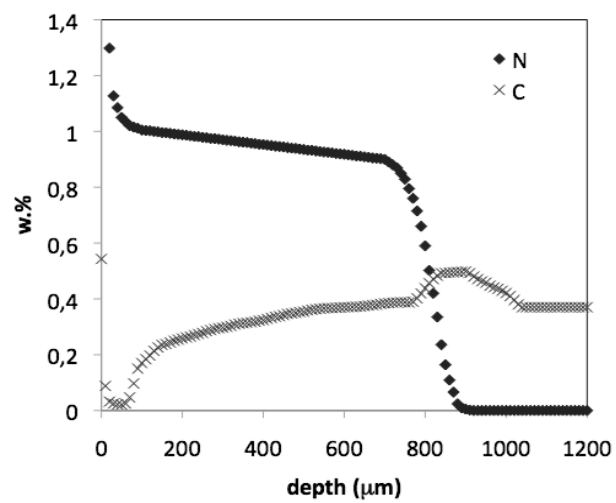

f.
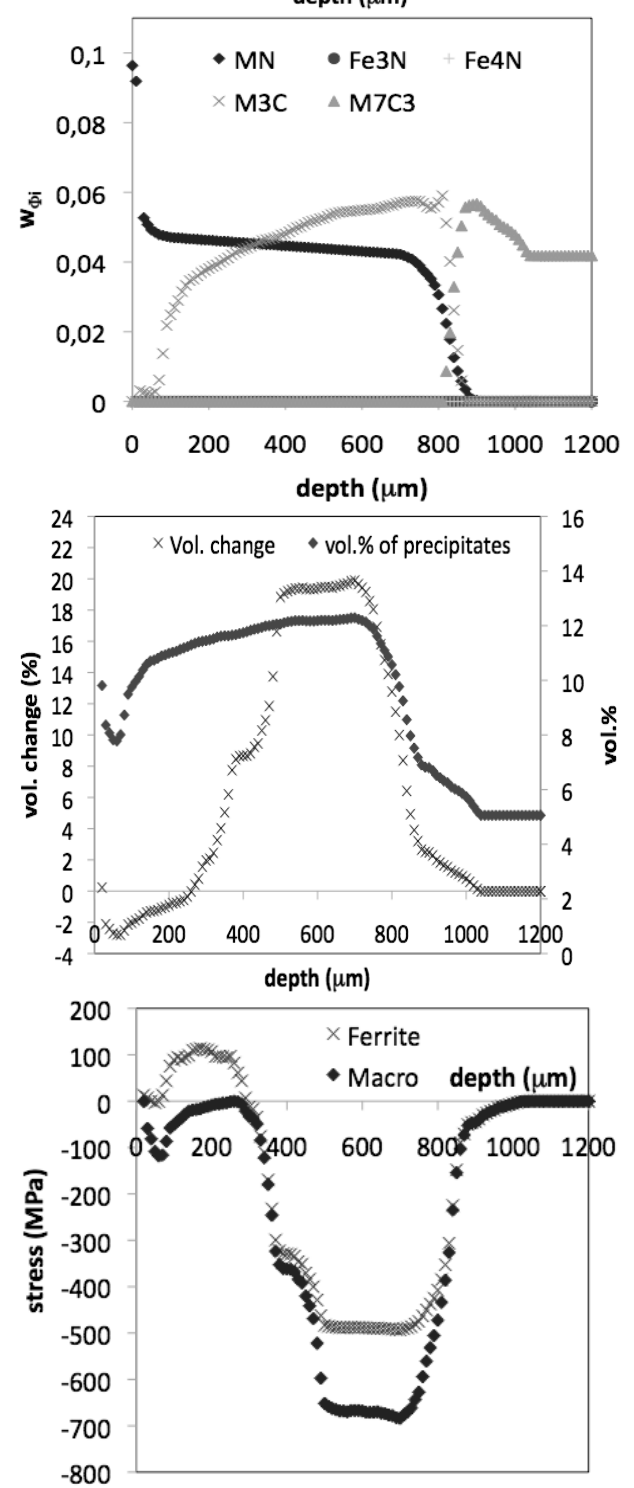

Fig. 1: Results from the nitriding model in case of an iron-based alloy $\mathrm{Fe}-\mathrm{C}-3 \% \mathrm{Cr}$ nitrided $10 \mathrm{~h}$ (a. to d.) and $100 \mathrm{~h}$ (e. to h.) at $550^{\circ} \mathrm{C}$. Nitrogen and carbon depth profiles were carried out by GDOES analysis. 


\section{Experimental Observations}

Fig. 2 presents the residual stress-depth profiles of specimen nitrided 10 and $100 \mathrm{~h}$ at $550^{\circ} \mathrm{C}$ and obtained by X-ray diffraction analysis. Both profiles are characterized by a maximum of stresses of -150 and $-90 \mathrm{MPa}$ respectively. As generally observed, residual stresses are decreasing when time increasing whereas the nitrided depth is increasing [23]. Moreover after 100h of nitriding, tensile stresses can be observed between 0 and $100 \mu \mathrm{m}$ as in case of modeled profiles and in relation with the carbon depletion close to the surface. However these profiles present much lower level of residual stresses than in case of computed stresses. The gap may be due to the non-complete kinetics until $100 \mathrm{~h}$ of nitriding. In fact, as an important unloading of the ferritic matrix is observed from the surface to $400 \mu \mathrm{m}$ depth using two increments of time, one can assume a smoother equilibrium establishment with smaller increments of time.

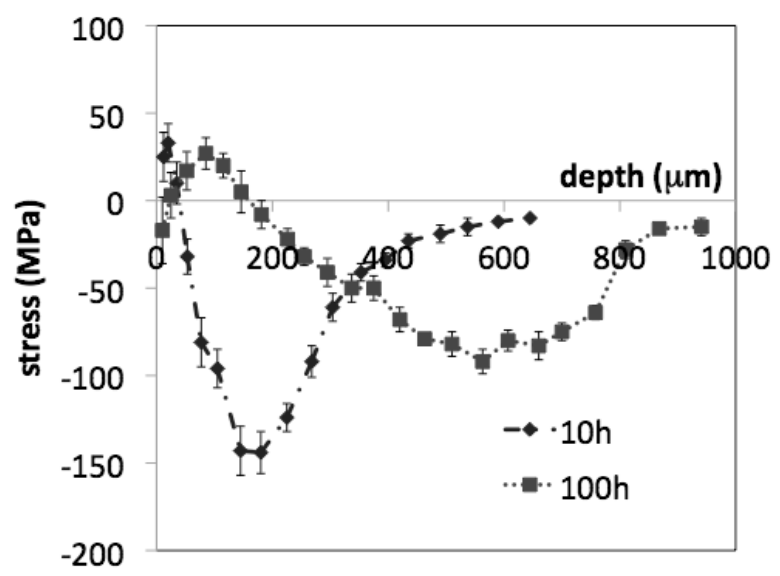

Fig. 2: residual stress-depth profiles $\left(\sigma_{11}-\sigma_{33}\right)$ of $\mathrm{Fe}-\mathrm{C}-3 \% \mathrm{Cr}$ alloy nitrided 10 and $100 \mathrm{~h}$ at $550^{\circ} \mathrm{C}$. Analysis carried out by conventional X-rays diffraction and the $\sin ^{2} \psi$ method.

\section{Conclusion}

The development of a model of nitriding is presented that take into account diffusion, precipitation and multi-scale mechanical descriptions. It is based on the volume change accompanying the precipitation during the process. The model is correlated partially to experimental X-rays analysis but the observed gap is coming from the non-complete kinetics of nitriding. The complex chemical and thermodynamical modifications during the treatment (interaction between nitrogen and carbon atoms), and so the kinetics of nitriding are of importance in order to correctly describe the residual stress development during nitriding. When nitriding is going on, nitriding-experienced depths see a decrease of residual stresses whereas nitrogen-free depths exhibit an increase of stresses in relation with nitrogen-carbon diffusion and the resulting phase transformations. In case of residual stress development of nitrided carbon iron-based alloy, the metallurgy takes advantage on the microstructure (coarsening of MN nitrides).

\section{References}

[1] H.C.F. Rozendaal, P.F. Colijn, E.J. Mittemeijer: Surf Eng, Vol. 5 (1985), p.30

[2] E.J. Mittemeijer: J Heat Treat, Vol. 3 (1983), p.114

[3] E.J. Mittemeijer: Mater Sci Forum, Vol. 223 (1992), p.102-104

[4] L. Barrallier, J. Barrallis: Proceedings of ICRS4 (1994), p.498-505

[5] H. Oettel, G. Schreiber: AWT-Tagungsband, Wiesbaden, Germany (1991), p.139-151

[6] E.J. Mittemeijer, A.B.P. Vogels, P.J. van der Schaaf: J Mater Sci, Vol. 3 (1980), p.153 
[7] N.E. Vives Diaz, R.E. Schacherl, L.F. Zagonel, E.J. Mittemeijer: Acta Mat, Vol. 56 (2008), p.1196-1208

[8] C. Ginter, L. Torchane, J. Dulcy: La Metallurgia Italiana, Vol. 7-8 (2006), p.29-35

[9] J.N. Locquet, L. Barrallier, R. Soto, A. Charaï: Micros Microanal Microstruct., Vol. 8 (1997), p.335-352

[10] M. Sennour, C. Jacq, C. Esnouf: J Mat Sci, Vol. 39 (2004), p.4533-4541

[11] M. Berveiller, A. Zaoui: J Mech Phy Sol, Vol. 26 (1979), p.325-344

[12] T. Murat, in: Micromechanics of Defects in Solids, Kluwer Academic Publishers (1991)

[13] P. Hadamar, E. Baeza, J.M. Sprauel, L. Barrallier: Proceedings of ICRS4 (1994), p.45-51

[14] S. Jegou, R. Kubler, L. Barrallier, F. Roch: Proceedings of ICRS8 (2008)

[15] Y. Sun, T. Bell: Heat Treat Met, Vol. 24 (1997), p.33

[16] M.A.J. Somers: J Phy IV, Vol. 120 (2004), p.21-33

[17] J. Crank, in: The Mathematics of Diffusion, Clarendon Press, Oxford (1975)

[18] M. Cherkaoui, M. Berveiller, H. Sabar: Int J Plast, Vol. 14 (1998), p.597-626

[19] L. Barrallier, J.M. Sprauel: Groupement français pour l'analyse des contraintes résiduelles par diffractométrie X (April 1992), p.131-138

[20] V. Goret, A. Fabre, L. Barrallier, P. Vardon: Proceedings of ECRS7 (2008), p.298-290

[21] L. Castex, J.L. Lebrun, G. Maeder, J.M. Sprauel: Publications Scientifiques et Techniques, Arts \& Metiers ParisTech (1981)

[22] T.K. Hirsch, A.D.S. Rocha, F.D. Ramos: Met Mat Trans A, Vol. 35A (2004), p.3523-3530

[23] J. Barrallis, L. Castex, J.C. Chaize: Mémoires et Études Scientifiques - Revue de Metallurgie (1986) 